\title{
The relation between promotional spending on drugs and their therapeutic gain: a cohort analysis
}

\author{
Joel Lexchin MSc MD
}

\section{Abstract}

Background: Whether drug promotion helps or hinders appropriate prescribing by physicians is debated. This study examines the most heavily promoted drugs and the therapeutic value of those drugs to help determine whether doctors should be using promotional material to inform themselves about drugs.

Methods: Lists were constructed of the 50 most heavily promoted drugs (amount of money spent on journal advertisements and visits by sales representatives) and the 50 top-selling drugs (by dollar value) for 2013, 2014 and 2015. Therapeutic gain was determined by examining ratings from the Patented Medicine Prices Review Board and the French drug bulletin Prescrire International and was categorized as major, moderate or little to none. For each of the 3 years, the number of drugs in the 3 therapeutic categories for drugs in both groups was compared. The amount and proportion of money spent on promotion for drugs in each of the 3 therapeutic categories for the 3 years was also determined.

Results: Therapeutic ratings were available for 42 of 79 of the most heavily promoted drugs over the 3 years and for 40 of 61 of the top-selling drugs. Nearly all the money spent on promotion in each of the 3 years went to drugs with little to no therapeutic gain. The distribution of therapeutic gain for drugs in both groups was statistically significantly different only in $2013(p=0.04)$.

Interpretation: Most of the money spent on promotion went to drugs that offer little to no therapeutic gain. This result calls into question whether doctors should read journal advertisements or see sales representatives to acquire information about important medical therapies.

$\mathrm{P}$ harmaceutical companies often claim that they promote their products to bring them to the attention of doctors and to inform doctors about them. This orientation is reflected in a statement about the role of pharmaceutical sales representatives issued by Rx\&D (now Innovative Medicines Canada): "Provider-supported detailing generates awareness about new treatments and provides science-based and Health Canada approved advice on how to administer these medications." ${ }^{1}$ Advertisements for medicines that appear in Canadian medical journals are screened by the independent Pharmaceutical Advertising Advisory Board to ensure compliance with the board's Code of Advertising Acceptance, a code that is endorsed by companies belonging to Innovative Medicines Canada. The mandate of the Pharmaceutical Advertising Advisory Board reads, in part: "The PAAB reviews materials developed by pharmaceutical manufacturers predominantly for the purpose of advertising or promoting ... a product to healthcare professionals and increasing their awareness of that brand."2
It is generally accepted that promotion influences physicians' prescribing behaviour. However, there is disagreement about whether the direction of that influence is toward moreor less-rational prescribing ${ }^{3,4}$ and, therefore, disagreement about the value of promotion. A recent study of the 25 most heavily promoted drugs in the United States showed that these products had limited therapeutic value. ${ }^{5}$ However, given differences between the Canadian and US markets, including their dollar value, the difference in the strictness of industry codes, the requirement in the US for companies to report payments of $\$ 10$ or more to physicians and the screening of

Competing interests: See the end of the article.

This article has been peer reviewed.

Correspondence to: Joel Lexchin, jlexchin@yorku.ca

CMAJ Open 2017. DOI:10.9778/cmajo.20170089 
journal advertisements by the Canadian Pharmaceutical Advertising Advisory Board, there is no a priori reason to believe that the situation in Canada is either the same as or different from the one south of the border.

This study looks at the most heavily promoted drugs and the therapeutic gain from those products. It also compares the therapeutic gain from the most-promoted drugs and the topselling drugs by dollar value. Examining whether the medicines that are heavily promoted are the ones that provide the most therapeutic gain may help in determining whether doctors should be using promotional material to inform themselves about therapeutically important drugs.

\section{Methods}

\section{Sources of data}

I used the annual reports from IMS I Brogan (now QuintilesIMS) as the primary source of data about the amount of money spent on journal advertisements and visits by sales representatives, and the top products by sales revenue, as this company is the only publicly available source that reports this type of information consistently from year to year. IMS I Brogan information is limited to the top 50 drugs in each of the 2 categories. IMS IBrogan sells data and reports to all the top 100 worldwide global pharmaceutical and biotechnology companies, as well as consulting firms, advertising agencies, government bodies and financial firms, ${ }^{6}$ and has produced reports for the Canadian federal government.?

From the reports for 2013, 2014 and $2015,^{8-10}$ I extracted the generic name, brand name and amount spent on promotion for the 50 most heavily promoted drugs in each year. For the 50 top-selling products in each year, I recorded the generic and brand names. The list of the top 50 products includes devices for measuring blood glucose level, and these were excluded from the analysis, as were generic drugs if the brand-name drug was also on the list of top 50 products. Different formulations of the same drug were treated as unique products.

\section{Determination of therapeutic gain}

I determined the therapeutic gain from products from information on the website of the Patented Medicine Prices Review Board (PMPRB) (www.pmprb-cepmb.gc.ca/ pmpMedicines.asp? $\mathrm{x}=611)$ and the independent French drug bulletin Prescrire International (http://english.prescrire.org/ en/Search.aspx; subscription required). I chose these sources because they both provide objective assessments of therapeutic value that do not require any subjective interpretation.

The PMPRB is a federal agency that is responsible for calculating the maximum introductory price for all new patented medications introduced onto the Canadian market. It is important to note that the PMPRB is not a payer, and, therefore, its decisions about therapeutic value are not influenced by how much it might have to pay for the product. As part of the process of determining the price, the PMPRB's independent Human Drug Advisory Panel determines the therapeutic value of each product it reviews; these evaluations are available on its website. The advisory panel determines the ratings

\begin{tabular}{|lll|}
\hline Table 1: Therapeutic rating scale* & \\
\hline Category & $\begin{array}{l}\text { Patented Medicine } \\
\text { Prices Review Board }\end{array}$ & $\begin{array}{c}\text { Prescrire } \\
\text { International† }\end{array}$ \\
\hline $\begin{array}{l}\text { Major } \\
\text { therapeutic gain }\end{array}$ & $\begin{array}{l}\text { Breakthrough } \\
\text { Substantial } \\
\text { improvement }\end{array}$ & $\begin{array}{l}\text { Bravo } \\
\text { A real advance }\end{array}$ \\
\hline $\begin{array}{l}\text { Moderate } \\
\text { therapeutic gain }\end{array}$ & $\begin{array}{l}\text { Moderate (primary or or } \\
\text { secondary) }\end{array}$ & $\begin{array}{l}\text { Offers an } \\
\text { advantage }\end{array}$ \\
\hline $\begin{array}{l}\text { Little to no } \\
\text { therapeutic gain }\end{array}$ & $\begin{array}{l}\text { Slight or no } \\
\text { improvement }\end{array}$ & $\begin{array}{l}\text { Possibly helpful } \\
\text { Nothing new } \\
\text { Not acceptable }\end{array}$ \\
\hline $\begin{array}{l}\text { *Ratings from the 2 organizations were grouped to make them comparable in } \\
\text { terms of their assessment of the new therapeutic value offered. } \\
\text { †The Prescrire category "judgment reserved" was not used. }\end{array}$ \\
\hline
\end{tabular}

for the drugs before the maximum price is established and uses a 4-point scale: breakthrough, substantial improvement, moderate (primary or secondary) improvement, and slight or no improvement. In deciding on the level of therapeutic innovation, the advisory panel considers 2 primary factors (increased efficacy, and reduction in the incidence or grade of important adverse reactions) and 9 secondary factors (route of administration, patient convenience, compliance improvements leading to improved therapeutic efficacy, caregiver convenience, time required to achieve the optimal therapeutic effect, duration of usual treatment course, success rate, proportion of affected population treated effectively and disability avoidance/savings). The primary factors are given the greatest weight, followed by an assessment of any additional improvement as a result of the secondary factors. ${ }^{11}$

Prescrire assesses the therapeutic value of medicines through a multistep process. First, it "examines the condition or clinical setting for which the drug is proposed; then the natural course of the disease, the efficacy and safety of existing treatments, and the most relevant outcome measures. This is followed by a systematic search for clinical data on the efficacy and adverse effects of the new drug, and an assessment of the level of evidence. Based on [its] independent analysis of clinical data, [it] form[s] a judgement as to whether or not the new drug is beneficial for patients or whether or not its harmful effects outweigh the benefit." ${ }^{12}$ Based on its analysis, Prescrire rates products using the following 7 categories: bravo (major therapeutic innovation in an area where previously no treatment was available), a real advance (important therapeutic innovation but has limitations), offers an advantage (some value but does not fundamentally change the present therapeutic practice), possibly helpful (minimal additional value and should not change prescribing habits except in rare circumstances), nothing new (may be a new molecule but is superfluous because it does not add to clinical possibilities offered by previously available products), not acceptable (without evident benefit but with potential or real disadvantages) or judgment reserved (decision postponed until better data are available and more thorough evaluation). ${ }^{13}$

I accessed assessments of additional therapeutic value by the PMPRB on its website. Prescrire reviews were down- 
loaded from its website. Reviews were then independently read by 2 reviewers (J.L. and a family physician) and the ratings recorded. There were no disagreements between the 2 reviewers.

\section{Analysis}

The categories used by the PMPRB and Prescrire were collapsed into 3 ratings of therapeutic gain: major therapeutic gain, moderate therapeutic gain and little to no therapeutic gain (Table 1). I assigned therapeutic gain for each of the most-promoted and top-selling drugs based on the rating scale. If both the PMPRB and Prescrire rated a drug and the ratings were different, I used the highest-ranking rating. For each of the 3 years, I compared the number of drugs in the 3 therapeutic categories for the most-promoted and topselling drugs using the Fisher exact test, with statistical significance set at $p<0.05$. The amount and proportion of money spent on promotion for drugs in each of the 3 therapeutic categories for the 3 years was also determined. Statistical calculations were done with Prism 7 (GraphPad Software).

\section{Ethics approval}

As this study did not involve any patients and all the material was publicly available, ethics review was not necessary.

\section{Results}

There were 79 unique most-promoted drugs over the 3 years. Therapeutic evaluations were available for 42 of these: $28 / 51$ in 2013, 29/50 in 2014 and 32/45 in 2015. (See Appendix 1, available at www.cmajopen.ca/content/5/3/E724/suppl/DC1, for a list of all the drugs, the amount spent on promoting them and their therapeutic rating, where available.) There were 66 unique top-selling products, of which 5 were excluded, 3 because they were instruments for measuring blood glucose level and 2 because they were generic products with the brand-name product also among the top 50 for the year. Among the remaining 61 drugs, therapeutic evaluations were available for 40:30/48 in 2013, 29/49 in 2014 and 29/46 in 2015. (See Appendix 2, available at www.cmajopen.ca/ content/5/3/E724/suppl/DC1, for a list of all the drugs and their therapeutic rating, where available.) Only 13 drugs were in both groups.

In the most heavily promoted group, the evaluations were done by both the PMPRB and Prescrire in 26 cases (discordant in 3 cases, with the PMPRB rating being higher in each case), by the PMPRB alone in 15 cases and by Prescrire alone in 1 case. In the top-selling group, the evaluation was done by both the PMPRB and Prescrire in 31 cases (discordant in 4 cases, with the PMPRB rating being higher in each case), by the PMPRB alone in 7 cases and by Prescrire alone in 2 cases. Few drugs provided major or moderate therapeutic gain. Of the most-promoted drugs, $90 \%-96 \%$ were rated as having little to no therapeutic gain; $77 \%-79 \%$ of the top-selling drugs were similarly rated (Table 2). The distribution of therapeutic gain for both groups was statistically significantly different only in $2013(p=0.04)$.

The fact that few to none of the most heavily promoted drugs offered a moderate or major therapeutic gain in each of the 3 years was reflected in the distribution of promotional expenditures. In 2013, $96.5 \%$ of the money spent went to drugs with little to no therapeutic gain, with the remaining $3.5 \%$ going to drugs with moderate therapeutic gain (Table 3 ). In 2014 and 2015, the proportion spent on drugs with little to no therapeutic gain was $92.0 \%$ and $93.8 \%$, respectively, and the most that went to drugs in the other categories was $5.7 \%$ for drugs with moderate therapeutic gain, in 2014.

\section{Interpretation}

Most of the money spent on promotion in the form of journal advertisements and visits by sales representatives in Canada goes to drugs that offer little to no therapeutic gain. Similarly, most of the top-selling drugs offer little to no therapeutic gain. The finding that there was a difference in therapeutic distribution between the most-promoted drugs and the topselling drugs in only 1 of the 3 years studied may mean that there are few therapeutically significant products that can be promoted. It is, of course, possible that this group of drugs is being promoted through other methods or that the minority of drugs with a high therapeutic value may sell well without the need to promote them.

Table 2: Therapeutic value of most-promoted and top-selling drugs

\begin{tabular}{|c|c|c|c|c|c|c|}
\hline \multirow[b]{3}{*}{ Category } & \multicolumn{6}{|c|}{ Year; no. (\%) of drugs } \\
\hline & \multicolumn{2}{|c|}{$2013^{*}$} & \multicolumn{2}{|c|}{$2014 \dagger$} & \multicolumn{2}{|c|}{$2015 \ddagger$} \\
\hline & $\begin{array}{c}\text { Most-promoted } \\
\text { drugs } \\
n=28\end{array}$ & $\begin{array}{c}\text { Top-selling } \\
\text { drugs } \\
n=30\end{array}$ & $\begin{array}{c}\text { Most-promoted } \\
\text { drugs } \\
n=29\end{array}$ & $\begin{array}{c}\text { Top-selling } \\
\text { drugs } \\
n=29\end{array}$ & $\begin{array}{c}\text { Most-promoted } \\
\text { drugs } \\
n=32\end{array}$ & $\begin{array}{c}\text { Top-selling } \\
\text { drugs } \\
n=29\end{array}$ \\
\hline Major therapeutic gain & $0(0)$ & $5(17)$ & $1(3)$ & $4(14)$ & $1(3)$ & $4(14)$ \\
\hline Moderate therapeutic gain & $1(4)$ & $2(7)$ & $2(7)$ & $2(7)$ & $2(6)$ & $2(7)$ \\
\hline Little to no therapeutic gain & $27(96)$ & $23(77)$ & $26(90)$ & $23(79)$ & $29(91)$ & $23(79)$ \\
\hline
\end{tabular}




\begin{tabular}{|lccc|}
\hline \multicolumn{3}{l}{$\begin{array}{l}\text { Table 3: Amount spent on journal advertising and sales representative visits by } \\
\text { therapeutic value }\end{array}$} \\
\cline { 2 - 4 } Category & \multicolumn{2}{c|}{ Year; amount spent, \$ thousands (\% of total) } \\
\hline & 2013 & 2014 & 2015 \\
\hline Major therapeutic gain & $0(0.0)$ & $3711(2.3)$ & $3359(1.6)$ \\
\hline Moderate therapeutic gain & $5816(3.5)$ & $9350(5.7)$ & $9268(4.5)$ \\
\hline Little to no therapeutic gain & $159999(96.5)$ & $149941(92.0)$ & $192644(93.8)$ \\
\hline Overall & $165815(100.0)$ & $163002(100.0)$ & $205271(100.0)$ \\
\hline
\end{tabular}

Promotional material does not appear to be a way for doctors to learn about therapeutically important products. Other factors besides therapeutic gain, including patient preferences, adverse reactions to specific drugs, insurance coverage and other medications a patient is taking, enter into decisions about what drug to prescribe to an individual patient. However, none of this information is available through promotional channels.

The pharmaceutical industry spent almost $\$ 563$ million in total on journal advertising and sales representative visits in 2015, with unknown amounts going to the 14 million samples left behind, ${ }^{10}$ engaging key opinion leaders to give talks, meetings, direct-to-consumer advertising, booths at medical conferences and other forms of promotion. In 2015 , just over a third of Canadian doctors were not seeing sales representatives, but $11 \%$ saw 6 or more a month, ${ }^{14}$ and in that year there was a total of 3720000 visits. ${ }^{10}$ The comprehensiveness of the safety information provided by sales representatives when they visit doctors was investigated in a study involving primary care practitioners in Vancouver and Montréal. ${ }^{15}$ Minimally adequate safety information, defined a priori as the mention of 1 or more of approved indications, serious adverse events, common nonserious adverse events or contraindications and no unapproved indications or unqualified safety claims (e.g., "this drug is safe"), was provided in $5 / 412(1.2 \%)$ promotions in Vancouver and $7 / 423(1.6 \%)$ in Montréal. Representatives did not provide any information about harms (a serious adverse event, a common adverse event or a contraindication) in two-thirds of interactions.

Innovative Medicines Canada, the organization representing the research-based companies, says on its website that its mandate is to provide "access to education and information about the appropriate uses of our products and services" to doctors. ${ }^{16}$ The findings of the current study and that by Mintzes and colleagues ${ }^{15}$ about sales representatives raise questions about whether this mandate is being fulfilled.

In a related study, Greenway and Ross ${ }^{5}$ used the Open Payments database set up under the US Physicians Payments Sunshine Act to look at the 25 drugs associated with the largest total payments to physicians and teaching hospitals, excluding research payments, royalties and licensing fees. They found that the most-promoted drugs included a significantly lower proportion of "first in class" or "advance in class" drugs compared to the 25 top-selling products and that the most-promoted group also contained significantly fewer prod- ucts listed on the World Health Organization's Essential Medicines List. ${ }^{17}$ The similarity in the findings between their study and the current one in terms of the therapeutic gain from heavily promoted products suggests that the pattern of how promotional spending is distributed may be present in multiple jurisdictions.

\section{Limitations}

The main limitation to this study is that therapeutic evaluations were available for only $53 \%$ of the most-promoted drugs and $66 \%$ of the top-selling ones. Therefore, distribution of therapeutic gain in both of these groups may have been different if larger numbers of products had been available for analysis. Neither the PMPRB nor Prescrire revisits their evaluations, except in cases in which the initial Prescrire rating is "judgment reserved," and it is possible that a reevaluation may have resulted in a different rating for some drugs. The conclusion about the therapeutic gain from the most-promoted products is based on money spent on journal advertising and visits by sales representatives. It is possible, although unlikely, that other forms of promotion are directed to products with a higher degree of therapeutic gain. There is the assumption that the evaluations by PMPRB and/or Prescrire represent a gold standard in the assessment of a drug's therapeutic gain. Although there is always a legitimate debate about therapeutic gain, the rigorous processes that these organizations use to arrive at their conclusions and their independence give strong face validity to their assessments. Finally, the results are limited to the top 50 drugs in either category and are applicable only to the 3 -year period studied.

\section{Conclusion}

The focus on promoting primarily drugs with little to no therapeutic gain calls into question the value of doctors' reading journal advertisements or seeing sales representatives if their purpose in doing so is to acquire information about important medical therapies. Further research should be directed into investigating the best ways of informing doctors about therapeutically important new drugs or new indications for existing drugs.

\section{References}

1. Rx\&D. Where we stand: detailing. Ottawa: Canada's Research-Based Pharmaceutical Companies; 2010:2. 
2. Code of Advertising Acceptance. Pickering (ON): Pharmaceutical Advertising Advisory Board; 2013. Available: www.paab.ca/paab-code.htm (accessed 2014 Sept. 13).

3. The facts about pharmaceutical marketing and promotion. Washington: Pharmaceutical Research and Manufacturers of America; 2008.

4. Spurling GK, Mansfield PR, Montgomery B, et al. Information from pharmaceutical companies and the quality, quantity, and cost of physicians' prescribing: a systematic review. PLoS Med 2010;7:e1000352.

5. Greenway T, Ross J. US drug marketing: How does promotion correspond with health value? BMF 2017;357:j1855.

6. Tanner A. Company that knows what drugs everyone takes going public. Forbes 2014 Jan. 6. Available: https://www.forbes.com/sites/adamtanner/2014/01/06/ company-that-knows-what-drugs-everyone-takes-going-public/-40258fa94c 90 (accessed 2017 July 31).

7. IMS Brogan. Canada's pharmaceutical industry and prospects. Ottawa: Industry Canada; 2014.

8. Canadian pharmaceutical industry review 2013. Montréal: IMS Health/Brogan; 2014. Available: http://imsbrogancapabilities.com/YIR_2013_FINAL (accessed 2017 Jan. 31).

9. Canadian pharmaceutical industry review 2014. Montréal: IMS Health/Brogan; 2015. Available: http://imsbrogancapabilities.com/YIR_2014_FINAL (accessed 2017 Jan. 31).

10. Canadian pharmaceutical industry review 2015. Montréal: IMS Health/Brogan; 2016. Available: http://imsbrogancapabilities.com/YIR_2015_FINAL (accessed 2017 Jan. 31).

11. Compendium of policies, guidelines and procedures - reissued June 2013. Ottawa: Patented Medicine Prices Review Board; 2014. Available: www. pmprb-cepmb.gc.ca/view.asp?ccid=492-1637 (accessed 2014 July 20).

12. Prescrire's ratings system: gauge the usefulness of new products at a glance. Paris: Prescrire; 2011. Available: http://english.prescrire.org/en/81/168/ 46800/0/NewsDetails.aspx (accessed 2015 Mar. 11).

13. Prescrire's rating system. Prescrire Int 2002;11:43.

14. Leslie C. Physician trends survey: relationship between MDs and pharma changing. Medical Post 2015 Sept. 15;45.
15. Mintzes B, Lexchin J, Sutherland J, et al. Pharmaceutical sales representatives and patient safety: a comparative prospective study of information quality in Canada, France and the United States. F Gen Intern Med 2013;28:1368-75.

16. Code of Ethical Practices. Ottawa: Innovative Medicines Canada; 2016. Available: http://innovativemedicines.ca/wp-content/uploads/2015/06/IMC_Code_ EN.pdf (accessed 2016 Oct. 18).

17. Essential medicines and health products. Geneva: World Health Organization; 2017. Available: www.who.int/medicines/publications/essentialmedicines/en/ (accessed 2017 Jan. 31).

Competing interests: In 2015-2017, Joel Lexchin received payment from 2 nonprofit organizations for being a consultant on a project looking at indication-based prescribing and a second project looking at which drugs should be distributed free of charge by general practitioners. In 2015, he received payment from a for-profit organization for being on a panel that discussed expanding drug insurance in Canada. He is on the Foundation Board of Health Action International. No other competing interests were declared.

Affiliations: School of Health Policy and Management (Lexchin), York University and University Health Network (Lexchin), Toronto, Ont.

Contributor: Joel Lexchin conceived and designed the study, obtained, analyzed and interpreted the data, and wrote the manuscript. He gave final approval of the version to be published and agreed to be accountable for all aspects of the work.

Acknowledgement: The author thanks Catherine Oliver for reading the therapeutic reviews.

Supplemental information: For reviewer comments and the original submission of this manuscript, please see www.cmajopen.ca/content/5/3/ E724/suppl/DC1. 